\title{
The Protective Effects of Glycyrrhetinic Acid and Chrysin against Ischemia-Reperfusion Injury in Rat Ovaries
}

\author{
Rauf Melekoglu (D), ${ }^{1}$ Osman Ciftci, ${ }^{2}$ Sevil Eraslan, ${ }^{3}$ Saadet Alan, ${ }^{4}$ and Nese Basak ${ }^{5}$ \\ ${ }^{1}$ Faculty of Medicine, Department of Obstetrics and Gynecology, University of Inonu, 44280 Malatya, Turkey \\ ${ }^{2}$ Faculty of Medicine, Department of Medical Pharmacology, University of Inonu, 44280 Malatya, Turkey \\ ${ }^{3}$ Department of Obstetrics and Gynecology, Elbistan State Hospital, 46300 Kahramanmaras, Turkey \\ ${ }^{4}$ Faculty of Medicine, Department of Pathology, University of Inonu, 44280 Malatya, Turkey \\ ${ }^{5}$ Faculty of Pharmacy, Department of Pharmaceutical Toxicology, University of Inonu, 44280 Malatya, Turkey
}

Correspondence should be addressed to Rauf Melekoglu; rmelekoglu@gmail.com

Received 14 August 2017; Revised 3 April 2018; Accepted 10 April 2018; Published 14 May 2018

Academic Editor: Ermanno Greco

Copyright (c) 2018 Rauf Melekoglu et al. This is an open access article distributed under the Creative Commons Attribution License, which permits unrestricted use, distribution, and reproduction in any medium, provided the original work is properly cited.

Objective. To evaluate the protective effects of glycyrrhetinic acid (GA) and chrysin (CH) on experimental ischemia-reperfusion $(\mathrm{I} / \mathrm{R})$ injury in rat ovaries using tissue oxidative stress marker levels, hormone levels, and histopathological scores. Methods. Sixty healthy rats were randomly divided into six equal groups: control, I/R, I/R + $\mathrm{CH}(50 \mathrm{mg} / \mathrm{kg} / \mathrm{day}), \mathrm{I} / \mathrm{R}+\mathrm{GA}(100 \mathrm{mg} / \mathrm{kg} / \mathrm{day}), \mathrm{CH}$ $(50 \mathrm{mg} / \mathrm{kg} /$ day $)$, and GA (100 mg/kg/day). Biochemical, hormonal, and histopathological evaluations were performed on blood and tissue samples 14 days after $\mathrm{CH}$ and GA treatment. Results. The antioxidant defense system parameters were significantly higher in the ovarian tissues of the I/R + CH and I/R + GA groups than in those of the I/R group. Serum follicle-stimulating hormone levels were significantly reduced, and serum anti-Müllerian hormone levels were significantly increased in rats treated with $\mathrm{CH}$ and GA compared with those in the I/R group. Additionally, the histopathological scores of the I/R + CH and I/R + GA groups were significantly improved compared with those of the I/R group. Conclusions. The significant improvements in tissue oxidative stress parameters, serum hormone levels, and histological scores observed in this study indicate that treatment with $\mathrm{CH}$ or GA may be a conservative approach to prevent I/R injury in adnexal torsion cases after the ovarian detorsion procedure.

\section{Introduction}

Ovarian torsion, defined as twisting of the ovary and its vascular peduncle around the axis of the suspensory ligament, accounts for nearly $3 \%$ of all gynecological emergencies [1]. Conditions that lead to ovarian enlargement, such as adnexal cysts, ovarian hyperstimulation, or pregnancy, and hyperlaxity of the ovary proprium and infundibulopelvic ligaments are considered risk factors for ovarian torsion [2]. Although it can occur in women of all ages, it is primarily seen in women of reproductive age [3]. Depending on the degree of torsion, venous return to the ovarian tissue decreases, and stromal edema and internal hemorrhage subsequently occur. If arterial blood flow ceases, ischemic and necrotic processes begin in the tissue. Early diagnosis and management are essential to protect ovarian function [4]. Recent studies have recommended conservative treatment with detorsion to preserve the twisted ovary even when it seems cyanotic. This detorsion procedure does not significantly increase the risk of pulmonary embolism, and oophorectomy is no longer preferred [5]. However, detorsion of the twisted ovary leads to another risk, ischemia/reperfusion ( $I / R)$ injury, which is related to reperfusion and neutrophil infiltration of the tissue. As a result of the reperfusion process, an excessive amount of molecular oxygen supplementation to the ovarian tissue occurs, and the production of reactive oxygen species (ROS) increases. These ROS cause cellular damage by attacking cellular membranes through the peroxidation of polyunsaturated fatty acids [6]. Several antioxidants have been found to be effective in the prevention of oxidative injury and inflammation in ovarian tissues exposed to I/R injury [7]. 
Chrysin $(\mathrm{CH})$ is a natural flavonoid found in honey, propolis, and many plant extracts. Numerous studies have demonstrated the antioxidant, anti-inflammatory, and antidiabetogenic effects of chrysin [8]. Glycyrrhetinic acid (GA) is an aglycone saponin extracted from licorice root that has been widely used for its well-known anti-inflammatory, antitumor, and antihepatitic effects [9]. The benefits of these antioxidants have been demonstrated in $\mathrm{I} / \mathrm{R}$ injuries in the heart and brain, but no studies have been conducted on the effects of $\mathrm{CH}$ or GA on I/R injury in ovarian tissue.

The objective of this study was to evaluate the protective effects of $\mathrm{GA}$ and $\mathrm{CH}$ in experimental I/R injury in rat ovaries using histopathological scores, biochemical lipid peroxidation markers, and hormonal assessment.

\section{Materials and Methods}

2.1. Chemicals. Chrysin was obtained from MP Biomedicals, LLC (Santa Ana, CA, USA). Glycyrrhetinic acid was obtained from Sigma Chemical Co. (St. Louis, MO, USA). All other chemicals for biochemical and histological analysis were purchased from Sigma Chemical Co. and were of analytical grade or the highest grade available.

2.2. Animals and Treatment. Experiments were performed under the animal ethics guidelines of the Inonu University Institutional Animals Ethics Committee (Approval No. 2016-A32). Sixty healthy adult female Wistar albino rats aged 3-4 months, obtained from the Experimental Animal Institute (Malatya, Turkey), were used in this experiment. Animals were housed in sterilized polypropylene rat cages under a 12/12-h light/dark cycle at an ambient temperature of $21^{\circ} \mathrm{C}$. Food and water were provided ad libitum. Rats were randomly divided into six equal groups as follows ( $n=10$ per group): control (sham-operated), I/R, $\mathrm{I} / \mathrm{R}+\mathrm{CH}$ (50 mg/kg/day), I/R + GA (100 mg/kg/day), $\mathrm{CH}$ (50 mg/kg/day), and GA (100 mg/kg/day). CH and GA were dissolved in corn oil and orally administered for 14 days by gavage. The dose and treatment period of GA and $\mathrm{CH}$ were chosen based on previous studies $[10,11]$. After the treatment course, the animals were euthanized without pain or distress using increasing doses of anesthetic (intraperitoneal lethal doses of pentobarbital; Bioveta, Inc., Ankara, Turkey), and the ovaries were removed for histopathological analyses. Blood samples were collected from the left ventricle with an injector under anesthesia. Tissues samples were stored at $-45^{\circ} \mathrm{C}$ in a deep freezer until the analyses were performed.

2.3. Surgical Procedures. All surgical interventions were carried out in a proper laboratory environment under sterile conditions. After the rats were weighed, ketamine $(50 \mathrm{mg} / \mathrm{kg}$ ) and xylazine $(10 \mathrm{mg} / \mathrm{kg})$ were injected intramuscularly for anesthesia. The rats were then placed in a dorsally recumbent position, and the surgical area was disinfected and dressed with sterile coverings. Surgery was performed at $36 \pm 1^{\circ} \mathrm{C}$ ambient temperature to prevent hypothermia. The abdomen was entered by making a longitudinal midline incision of approximately $2 \mathrm{~cm}$ in the subabdominal area to reveal the ovaries. The I/R model was constructed by placing vascular clamps approximately $1 \mathrm{~cm}$ under the adnexal structure to simulate ovarian torsion. After $2 \mathrm{~h}$ of simulated torsion, the vascular clamps were opened to allow reperfusion, and the incision line was closed with 4-0 nylon sutures.

2.4. Biochemical Assay. Tissues were homogenized using a Teflon glass homogenizer in $150 \mathrm{mM} \mathrm{KCl} \mathrm{(pH} \mathrm{7.4)}$ at a $1: 10(\mathrm{w} / \mathrm{v})$ dilution of the whole homogenate. The homogenates were centrifuged at $18,000 \times \mathrm{g}$ at $4^{\circ} \mathrm{C}$ for $30 \mathrm{~min}$ to determine the malondialdehyde (MDA) and reduced glutathione (GSH) concentrations and superoxide dismutase (SOD) and catalase (CAT) activities or at $25,000 \times \mathrm{g}$ for $50 \mathrm{~min}$ to determine glutathione peroxidase (GPx) activity. The levels of MDA, an index of lipid peroxidation, were determined via thiobarbituric acid reaction using the method described by Yagi [12]. The product was evaluated spectrophotometrically at $532 \mathrm{~nm}$, and the results are expressed as nmol/g tissue. The method of Sedlak and Lindsay was used to determine the reduced GSH content of the ovarian homogenate at $412 \mathrm{~nm}$ [13]. The results are expressed as $\mathrm{nmol} / \mathrm{mL}$ tissue. GPx activity was determined according to the method developed by Paglia and Valentine [14]. In the presence of GSH reductase and nicotinamide adenine dinucleotide phosphate (NADPH), oxidized glutathione is immediately converted to its reduced form in conjunction with the oxidation of NADPH to NADP. The decrease in absorbance at $340 \mathrm{~nm}$ was measured, and GPx activity is presented as $\mathrm{U} / \mathrm{mg}$ protein. Copper-zinc SOD activity was measured as the inhibition of nitroblue tetrazolium reduction as a result of oxygen generation by the xanthine/xanthine oxidase system [15]. The resulting products, which were evaluated at $560 \mathrm{~nm}$, are expressed as $\mathrm{U} / \mathrm{mg}$ protein. The CAT activity of the tissues was measured according to the method of Aebi [16]. The enzymatic decomposition of hydrogen peroxide was monitored as the decrease in absorbance at $240 \mathrm{~nm}$. Enzyme activities are expressed as $\mathrm{kU} / \mathrm{mg}$ protein. The method established by Lowry et al. using bovine serum albumin as a standard was used to determine tissue protein content [17].

2.5. Hormonal Assay. Estradiol ( $\left.\mathrm{E}_{2}\right)$, follicle-stimulating hormone (FSH), luteinizing hormone (LH), and anti-Müllerian hormone $(\mathrm{AMH})$ were quantitatively estimated in rat serum samples using enzyme-linked immunosorbent assay (ELISA) kits (catalog numbers: SL0268Ra, SL0297Ra, SL1093Ra, and SL0504Ra, resp.; Sunlong Biotech Co., Ltd., Zhejiang, China). The $\mathrm{E}_{2}$ assay measured concentrations in the range of $5-150 \mathrm{pg} / \mathrm{mL}$, with manufacturer-specified interassay coefficients of variation (CV) of $7.5 \%$ and intra-assay CVs of $5.4 \%$. The FSH assay measured concentrations from 0.5 to $10 \mathrm{IU} / \mathrm{L}$; the serum inter- and intra-assay CVs were 6.4 and $4.3 \%$, respectively. The $\mathrm{LH}$ assay measured concentrations to $7 \mathrm{IU} / \mathrm{L}$ with a minimum detectable concentration of $0.1 \mathrm{IU} / \mathrm{L}$. The serum inter- and intra-assay CVs were 6.8 and $2.8 \%$, respectively. The AMH assay measured concentrations with an assay range of $0.5-20 \mathrm{ng} / \mathrm{mL}$; the manufacturer-specified mean interassay $\mathrm{CV}$ was $6.5 \%$, and the mean intra-assay $\mathrm{CV}$ was $4.0 \%$. 
TABLE 1: Levels of oxidant and antioxidant parameters in rat ovarian tissues among the treatment groups.

\begin{tabular}{|c|c|c|c|c|c|}
\hline Group & MDA (nmol/g tissue) & GSH (nmol/mL tissue) & SOD (U/mg protein) & GPx (U/mg protein) & CAT $(\mathrm{kU} / \mathrm{mg}$ protein) \\
\hline Control & $6.38 \pm 1.12^{\mathrm{a}}$ & $55.4 \pm 2.66^{\mathrm{f}}$ & $80.1 \pm 10.2^{\mathrm{k}}$ & $596.4 \pm 45.9^{\mathrm{p}}$ & $0.014 \pm 0.001^{\mathrm{v}}$ \\
\hline $\mathrm{I} / \mathrm{R}$ & $9.16 \pm 0.98$ & $35.5 \pm 2.87$ & $57.6 \pm 14.7$ & $468.9 \pm 92.6$ & $0.005 \pm 0.001$ \\
\hline $\mathrm{I} / \mathrm{R}+\mathrm{CH}$ & $5.02 \pm 1.05^{\mathrm{b}}$ & $45.2 \pm 3.56^{\mathrm{g}}$ & $75.1 \pm 15.1^{1}$ & $595.0 \pm 67.9^{\mathrm{r}}$ & $0.010 \pm 0.004^{\mathrm{x}}$ \\
\hline $\mathrm{I} / \mathrm{R}+\mathrm{GA}$ & $5.14 \pm 1.23^{c}$ & $50.9 \pm 3.44^{\mathrm{h}}$ & $78.3 \pm 12.6^{\mathrm{m}}$ & $608.8 \pm 52.3^{\mathrm{s}}$ & $0.011 \pm 0.005^{\mathrm{y}}$ \\
\hline $\mathrm{CH}$ & $5.94 \pm 1.09^{d}$ & $59.5 \pm 3.82^{\mathrm{i}}$ & $83.1 \pm 11.5^{\mathrm{n}}$ & $612.4 \pm 79.1^{\mathrm{t}}$ & $0.011 \pm 0.001^{\mathrm{w}}$ \\
\hline GA & $6.23 \pm 1.34^{\mathrm{e}}$ & $54.7 \pm 4.12^{\mathrm{j}}$ & $89.9 \pm 18.3^{\circ}$ & $626.3 \pm 88.4^{\mathrm{u}}$ & $0.012 \pm 0.002^{z}$ \\
\hline
\end{tabular}

TABLE 2: Histopathological scores among treatment groups.

\begin{tabular}{|c|c|c|c|c|c|c|}
\hline Histopathological score (mean \pm SD) & Hemorrhage & Edema & Vascular congestion & PMNL & Vascular proliferation & Apoptosis \\
\hline Control & $0 \pm 0^{\mathrm{a}}$ & $0.5 \pm 0.1^{\mathrm{f}}$ & $0.75 \pm 0.1^{\mathrm{k}}$ & $0.75 \pm 0^{\mathrm{p}}$ & $1 \pm 0.5^{\mathrm{u}}$ & $0.25 \pm 0.1^{\alpha}$ \\
\hline $\mathrm{I} / \mathrm{R}$ & $2.5 \pm 0.5$ & $3 \pm 0$ & $3 \pm 0$ & $3 \pm 0$ & $3 \pm 0$ & $1 \pm 0.5$ \\
\hline $\mathrm{I} / \mathrm{R}+\mathrm{CH}$ & $0 \pm 0^{\mathrm{b}}$ & $1 \pm 0^{g}$ & $1.25 \pm 0.5^{1}$ & $0.25 \pm 0.1^{\mathrm{q}}$ & $0.5 \pm 0^{\mathrm{v}}$ & $0.5 \pm 0.5^{\beta}$ \\
\hline $\mathrm{I} / \mathrm{R}+\mathrm{GA}$ & $0 \pm 0^{c}$ & $1 \pm 0^{\mathrm{h}}$ & $1.25 \pm 0.5^{\mathrm{m}}$ & $0 \pm 0^{\mathrm{r}}$ & $1 \pm 0.2^{\mathrm{x}}$ & $0.75 \pm 0.5^{\gamma}$ \\
\hline $\mathrm{CH}$ & $0 \pm 0.1^{\mathrm{d}}$ & $0.5 \pm 0.2^{\mathrm{i}}$ & $1 \pm 0^{\mathrm{n}}$ & $1 \pm 0^{s}$ & $1.25 \pm 0.25^{\mathrm{y}}$ & $0.75 \pm 0.2^{\lambda}$ \\
\hline GA & $0 \pm 0^{\mathrm{e}}$ & $0.75 \pm 0.1^{j}$ & $1.25 \pm 0^{\circ}$ & $1.75 \pm 0.5^{\mathrm{t}}$ & $2 \pm 0^{z}$ & $0.25 \pm 0.2^{\psi}$ \\
\hline
\end{tabular}

${ }^{\mathrm{a}} P=0.001,{ }^{\mathrm{b}} P<0.001,{ }^{\mathrm{c}} P<0.001,{ }^{\mathrm{f}} P<0.001,{ }^{\mathrm{g}} P<0.001,{ }^{\mathrm{h}} P<0.001,{ }^{\mathrm{k}} P<0.001,{ }^{1} P=0.001,{ }^{\mathrm{m}} P=0.001,{ }^{\mathrm{p}} P<0.001,{ }^{\mathrm{q}} P<0.001,{ }^{\mathrm{r}} P<0.001$,

${ }^{\mathrm{u}} P<0.001,{ }^{\mathrm{v}} P<0.001,{ }^{\mathrm{x}} P<0.001,{ }^{\alpha} P=0.003,{ }^{\beta} P=0.008,{ }^{\gamma} P=0.007$ compared with $\mathrm{I} / \mathrm{R}$ group, ${ }^{\mathrm{d}} P=0.748,{ }^{\mathrm{e}} P=1.000,{ }^{\mathrm{i}} P=0.950,{ }^{\mathrm{j}} P=0.089$,

${ }^{\mathrm{n}} P=0.645,{ }^{\mathrm{o}} \mathrm{P}=0.037,{ }^{\mathrm{s}} \mathrm{P}=0.527,{ }^{\mathrm{t}} \mathrm{P}=0.009,{ }^{\mathrm{y}} \mathrm{P}=0.665,{ }^{\mathrm{z}} \mathrm{P}=0.009,{ }^{\lambda} \mathrm{P}=0.003,{ }^{\psi} \mathrm{P}=0.954$ compared with the control group; $\mathrm{I} / \mathrm{R}$, ischemia-reperfusion; $\mathrm{CH}$, chrysin; GA, glycyrrhetinic acid; PMNL, polymorphonuclear leukocytes.

2.6. Histopathological Examination. The ovarian tissues were maintained in $10 \%$ formaldehyde solution for histopathological examination. Following routine procedures, embedded tissues were cut into $5 \mu \mathrm{m}$ thick sections and stained with hematoxylin and eosin $(\mathrm{H} \& \mathrm{E})$. Tissue damage was histopathologically assessed for hemorrhage, vascular congestion, edema, polymorphonuclear leukocyte (PMNL) infiltration, and apoptosis. At least five microscopic regions were examined to score the specimens semiquantitatively. Each sample was scored for each criterion using a scale ranging from 0 to 3 ( 0 , none; 1 , mild; 2 , moderate; 3 , severe). Total scores were calculated from these parameters. Histopathological evaluations were performed using a light microscope (Olympus BX51; Olympus Corporation, Tokyo, Japan).

2.7. Statistical Analysis. All values are presented as the mean \pm standard deviation. Differences were considered significant at $P<0.01$. SPSS software (ver. 18.0; SPSS, Inc., Chicago, IL, USA) was used to perform statistical analyses. The biochemical values were analyzed using one-way ANOVA and Tukey's post hoc honestly significant difference test. Histological results were compared using the Kruskal-Wallis variance analysis. When differences among the groups were detected, group means were compared using the Mann-Whitney $U$ test.

\section{Results}

3.1. Biochemical Results. The antioxidant (SOD, CAT, GPx, and GSH) and oxidant (MDA) parameters in the rat ovaries among different treatment groups are presented in Table 1. The I/R group had significantly higher ovarian tissue MDA levels than the control group had $(P<0.001)$, whereas the GSH levels and SOD, GPx, and CAT activities were significantly lower in the $\mathrm{I} / \mathrm{R}$ group than in the control group. MDA levels were significantly decreased, whereas GSH levels and CAT and SOD activities were significantly increased in ovarian tissues in the $\mathrm{I} / \mathrm{R}+\mathrm{CH}$ and $\mathrm{I} / \mathrm{R}+\mathrm{GA}$ groups compared with the I/R group. Treatment with $\mathrm{CH}$ or GA in the absence of $I / R$ injury improved tissue oxidative stress markers, such as GSH levels and SOD and GPX activities.

3.2. Histological Results. The histopathological scores for all six groups are listed in Table 2. Vascular congestion, hemorrhage, edema, PMNL infiltration, and apoptosis were significantly higher in the I/R group than in the control group. All histological parameters were significantly improved with the administration of $\mathrm{CH}$ or GA. The anti-inflammatory effects of GA and $\mathrm{CH}$ were also shown in the treatment group without I/R injury. The ovarian histopathological changes for $\mathrm{I} / \mathrm{R}, \mathrm{I} / \mathrm{R}+\mathrm{CH}$, and $\mathrm{I} / \mathrm{R}+\mathrm{GH}$ are shown in Figure 1. 


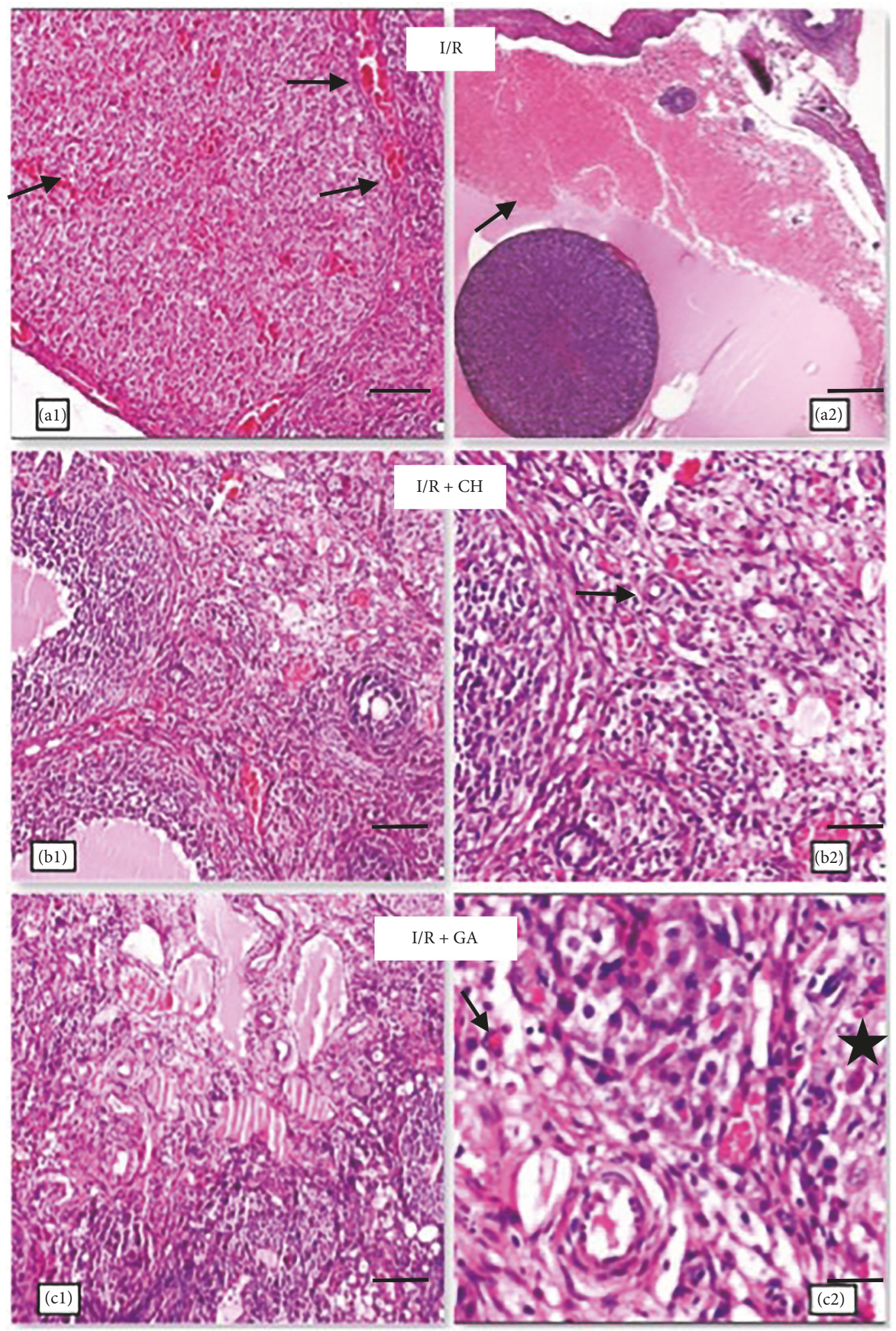

Figure 1: (a1, a2): ischemia-reperfusion (I/R) group. (a1) Vascular congestion indicated by $\uparrow$ symbol. (a2) Hemorrhage indicated by $\uparrow$ symbol ((a1): hematoxylin and eosin (H\&E), 100x, scale bar $=100 \mu \mathrm{m}$; (a2): H\&E, 40x, scale bar $=400 \mu \mathrm{m})(\mathrm{b} 1)$, (b2): I/R + chrysin $(\mathrm{CH})$ group. Decreased vascular proliferation indicated by $\uparrow$ symbol ((b1): HE, 100x, scale bar $=200 \mu \mathrm{m}$; (b2): HE, 200x, scale bar $=100 \mu \mathrm{m})$. (c1), (c2): I/R + glycyrrhetinic acid (GA) group. Reduced PMNL infiltration is indicated by $\uparrow$ symbol, and I/R-induced apoptosis is indicated by $\mathrm{Q}$ symbol. ((c1): HE, 100x, scale bar $=100 \mu \mathrm{m}$; (c2): HE, 400x, scale bar $=25 \mu \mathrm{m})$. 
TABLE 3: Serum hormone levels among the treatment groups.

\begin{tabular}{lcccc}
\hline Group & $\mathrm{E}_{2}(\mathrm{pg} / \mathrm{mL})$ & FSH $(\mathrm{IU} / \mathrm{L})$ & $\mathrm{LH}(\mathrm{IU} / \mathrm{L})$ & $\mathrm{AMH}(\mathrm{ng} / \mathrm{mL})$ \\
\hline Control & $73.5 \pm 5.56^{\mathrm{a}}$ & $2.22 \pm 0.31^{\mathrm{f}}$ & $3.24 \pm 0.13^{\mathrm{k}}$ & $7.54 \pm 0.77^{\mathrm{p}}$ \\
$\mathrm{I} / \mathrm{R}$ & $33.2 \pm 3.61$ & $5.25 \pm 1.00$ & $4.76 \pm 0.18$ & $3.47 \pm 0.54$ \\
$\mathrm{I} / \mathrm{R}+\mathrm{CH}$ & $66.7 \pm 5.25^{\mathrm{b}}$ & $3.94 \pm 0.48^{\mathrm{g}}$ & $3.13 \pm 0.36^{\mathrm{l}}$ & $5.36 \pm 0.31^{\mathrm{r}}$ \\
$\mathrm{I} / \mathrm{R}+\mathrm{GA}$ & $62.9 \pm 3.79^{\mathrm{c}}$ & $3.98 \pm 0.28^{\mathrm{h}}$ & $3.10 \pm 0.11^{\mathrm{m}}$ & $5.85 \pm 0.60^{\mathrm{s}}$ \\
$\mathrm{CH}$ & $74.5 \pm 6.69^{\mathrm{d}}$ & $3.29 \pm 0.44^{\mathrm{i}}$ & $3.11 \pm 0.11^{\mathrm{n}}$ & $7.81 \pm 0.74^{\mathrm{t}}$ \\
$\mathrm{GA}$ & $71.3 \pm 6.18^{\mathrm{e}}$ & $2.71 \pm 0.28^{\mathrm{j}}$ & $3.24 \pm 0.04^{\mathrm{o}}$ & $7.81 \pm 0.32^{\mathrm{u}}$ \\
\hline
\end{tabular}

${ }^{\mathrm{a}} P<0.001,{ }^{\mathrm{b}} P<0.001,{ }^{\mathrm{c}} P<0.001,{ }^{\mathrm{f}} P<0.001,{ }^{\mathrm{g}} P=0.002,{ }^{\mathrm{h}} P=0.001,{ }^{\mathrm{k}} P=0.004,{ }^{1} P=0.003,{ }^{\mathrm{m}} P=0.003,{ }^{\mathrm{p}} P<0.001,{ }^{\mathrm{r}} P=0.007,{ }^{\mathrm{s}} P=0.005$ compared with the I/R group, ${ }^{\mathrm{d}} P=0.848,{ }^{\mathrm{e}} P=0.570,{ }^{\mathrm{i}} P=0.042,{ }^{\mathrm{j}} P=0.095,{ }^{\mathrm{n}} P=0.754,{ }^{\mathrm{o}} P=0.954,{ }^{\mathrm{t}} P=0.043,{ }^{\mathrm{u}} P=0.043$ compared with the control group; I/R: ischemia-reperfusion; $\mathrm{CH}$ : chrysin; GA: glycyrrhetinic acid; $\mathrm{E}_{2}$ : estradiol, FSH: follicle-stimulating hormone; LH: luteinizing hormone; AMH: anti-Müllerian hormone.

3.3. Hormonal Assessment. The serum $\mathrm{E}_{2}$ and AMH levels were significantly lower, and the serum FSH and LH levels significantly higher, in the I/R group than in the control group. The results indicated a significant reduction in serum FSH and LH levels in rats treated with $\mathrm{CH}$ or GA compared with the I/R group. Additionally, the serum levels of $\mathrm{E}_{2}$ and $\mathrm{AMH}$ in rats treated with $\mathrm{CH}$ and $\mathrm{GA}$ were significantly higher than those of the I/R group. The effects of CH and GA on ovarian reserve markers are shown in Table 3.

\section{Discussion}

In this study, we examined the ovarian protective effects of $\mathrm{GA}$ and $\mathrm{CH}$ in a rat model of ovarian I/R injury. We demonstrated that $\mathrm{I} / \mathrm{R}$ injury alone caused a marked decrease in ovarian reserve, which was associated with increased tissue oxidative stress, impaired hormonal changes, and increased histopathological damage. In contrast, the tissue oxidative stress parameters, ovarian reserve markers, and histopathological changes were significantly ameliorated in rats that received $\mathrm{GA}$ or $\mathrm{CH}$ after $\mathrm{I} / \mathrm{R}$ injury. Ovarian detorsion without oophorectomy can protect ovarian function, but prophylactic measures are required against I/R injury after the procedure. The exact mechanism of cellular damage after I/R remains unclear. The induction of apoptosis by damaged mitochondrial proteins as a result of ischemia, activation of chemotaxis, and endothelial adhesion of leukocytes by impaired membrane proteins and phospholipids owing to the lipid peroxidation effects of ROS have been proposed as mechanisms in the pathophysiology [18]. ROS induces cellular damage through the overproduction of oxygen free radicals such as superoxide anions $\left(\mathrm{O}_{2}{ }^{-}\right)$, hydrogen peroxide $\left(\mathrm{H}_{2} \mathrm{O}_{2}{ }^{-}\right)$, hypochlorous acid $\left(\mathrm{HOCl}^{-}\right)$, and hydroxyl radicals $\left(\mathrm{OH}^{-}\right)$[19]. For this reason, several studies have focused on pharmaceutical agents with antioxidant and/or antiinflammatory effects to prevent ovarian I/R injury in animal models $[20,21]$. To the best of our knowledge, this is the first study to use $\mathrm{CH}$ and GA to treat I/R injury in ovarian torsion, and our results suggest that both of these pharmaceutical agents have protective effects against I/R injury.

The exact mechanism of the antioxidative and antiinflammatory effects of $\mathrm{CH}$ and GA is unclear. The antioxidative properties of $\mathrm{CH}$ have been attributed to the inhibition of inducible nitric oxide synthase and cyclooxygenase-2 expression, and the inhibition of proinflammatory nuclear factor kappa $\mathrm{B}(\mathrm{NF}-\kappa \mathrm{B})$ activity has been suggested as the mechanism for the anti-inflammatory effects of $\mathrm{CH}$ [22]. It has also been proposed that the antioxidative and anti-inflammatory effects of GA may be attributed to inhibition of the complement pathway and the suppression of lipopolysaccharideinduced tumor necrosis factor alpha production and NF- $\kappa \mathrm{B}$ activation [23]. The results of this study also confirmed the antioxidative and anti-inflammatory effects of $\mathrm{CH}$ and GA by demonstrating their protective effects against I/R injury in rat ovaries, such as reducing lipid peroxidation, increasing antioxidant activity, and improving histopathological scores.

MDA is one of the end products of lipid peroxidation, and increased MDA levels reflect oxidative stress. In contrast, elevated GSH levels and increased SOD, CAT, and GPx activities indicate tissue healing after oxidative damage [24]. In this study, we demonstrated a significant improvement in tissue oxidative stress markers MDA, GSH, SOD, CAT, and GPx. Consistent with our results, Yao et al. reported that $75 \mathrm{mg} / \mathrm{kg} /$ day $\mathrm{CH}$ was effective in preventing focal cerebral I/R injury, and they found that SOD activity significantly increased, and MDA content significantly decreased, in the $\mathrm{CH}$ treatment group after I/R injury [25]. Yildirim et al. investigated the effects of octreotide treatment for the prevention of $\mathrm{I} / \mathrm{R}$ injury in rat ovaries, and they attributed decreased tissue MDA levels to the antioxidant properties of octreotide [26].

Our results also revealed that $\mathrm{CH}$ and GA had beneficial effects on ovarian functional restoration after I/R injury. $\mathrm{AMH}$ and $\mathrm{E}_{2}$ levels were significantly increased, and FSH and LH levels significantly decreased, in the $\mathrm{CH}$ and GA treatment groups compared with the I/R injury group. Experimental studies on the effects of I/R injury and antioxidants on ovarian reserve markers are limited. Özcan et al. evaluated the effects of resveratrol against oxidative damage stimulated by cisplatin administration on ovarian reserve in rats. They found that resveratrol treatment significantly increased $\mathrm{AMH}$ levels compared with those in the control group [27]. Sahin Ersoy et al. compared the effects of N-acetylcysteine (NAC) and enoxaparin on ovarian tissue preservation by assessing ovarian reserve and oxidative stress markers following ovarian torsion/detorsion injury. They noted that NAC administration resulted in more preantral follicles and significantly 
higher AMH levels compared with enoxaparin treatment and I/R injury [28].

In the present study, we showed that $\mathrm{CH}$ and GA treatment ameliorated histological changes such as vascular congestion, hemorrhage, edema, and inflammatory cell infiltration in ovarian tissue following $2 \mathrm{~h}$ of clamping ovarian vessels with atraumatic vessel clips to stimulate ovarian torsion. Tang et al. showed the beneficial effects of glycyrrhizin (which includes GA) on endotoxin-induced acute liver injury after partial hepatectomy in rats. They reported significantly improved histological scores in the liver following glycyrrhizin treatment [29]. Similarly, beneficial effects of sildenafil, montelukast, clotrimazole, and infliximab have been shown in many studies of I/R injury in rat ovaries due to the antioxidant and anti-inflammatory properties of these agents. All of these pharmacological agents have been associated with improvements in histopathological parameters such as vascular congestion, edema, and leukocyte infiltration [30-33].

The main limitation of this study was that only a single dose of $\mathrm{CH}$ and GA was examined; different doses of these agents may have different effects. Additionally, we did not perform a preliminary study, and the duration and administration routes of $\mathrm{CH}$ and $\mathrm{GA}$ were determined based on previous studies. This failure to examine the optimal doses and duration for $\mathrm{CH}$ and GA treatments may be addressed in future studies.

\section{Conclusion}

In conclusion, treatment of ovarian $\mathrm{I} / \mathrm{R}$ injury with $\mathrm{CH}$ and GA was effective in reducing ovarian damage. The significant improvements in tissue oxidative stress markers, serum hormone levels, and histopathological scores detected in this study indicate that treatment with $\mathrm{CH}$ or GA may be a conservative approach for adnexal torsion cases after the detorsion procedure to prevent I/R injury. The beneficial effects of these agents may be attributed to the antioxidant and anti-inflammatory effects of $\mathrm{CH}$ and GA.

\section{Disclosure}

The institute where the work was conducted is Faculty of Medicine, the University of Inonu. The English in this document has been checked by at least two professional editors, both native speakers of English. For a certificate, please see: http://www.textcheck.com/certificate/MMinfs.

\section{Conflicts of Interest}

The authors declare no conflicts of interest regarding the publication of this article.

\section{Acknowledgments}

This research was supported by the Research Fund of Inonu University (Project no. 2016/62).

\section{References}

[1] C. Huchon and A. Fauconnier, "Adnexal torsion: a literature review," European Journal of Obstetrics \& Gynecology and Reproductive Biology, vol. 150, no. 1, pp. 8-12, 2010.

[2] Z. Tsafrir, F. Azem, J. Hasson et al., "Risk factors, symptoms, and treatment of ovarian torsion in children: The twelveyear experience of one center," Journal of Minimally Invasive Gynecology, vol. 19, no. 1, pp. 29-33, 2012.

[3] K. J. Sasaki and C. E. Miller, "Adnexal Torsion: Review of the Literature," Journal of Minimally Invasive Gynecology, vol. 21, no. 2, pp. 197-202, 2014.

[4] G. Harkins, "Ovarian torsion treated with untwisting: Second look 36 hours after untwisting," Journal of Minimally Invasive Gynecology, vol. 14, no. 3, p. 270, 2007.

[5] J. H. Becker, J. D. Graaff, and C. M. Vos, "Torsion of the ovary: A known but frequently missed diagnosis," European Journal of Emergency Medicine, vol. 16, no. 3, pp. 124-126, 2009.

[6] C. Li and R. M. Jackson, "Reactive species mechanisms of cellular hypoxia-reoxygenation injury," American Journal of Physiology-Cell Physiology, vol. 282, no. 2, pp. C227-C241, 2002.

[7] B. Prieto-Moure, J. M. Lloris-Carsí, C. Barrios-Pitarque et al., "Pharmacology of Ischemia-Reperfusion. Translational Research Considerations," Journal of Investigative Surgery, vol. 29, no. 4, pp. 234-249, 2016.

[8] R. Khan, A. Q. Khan, W. Qamar et al., "Chrysin protects against cisplatin-induced colon. toxicity via amelioration of oxidative stress and apoptosis: probable role of p38MAPK and p53," Toxicology and Applied Pharmacology, vol. 258, no. 3, pp. 315329, 2012.

[9] H. Yamaguchi, T. Noshita, T. Yu et al., "Novel effects of glycyrrhetinic acid on the central nervous system tumorigenic progenitor cells: Induction of actin disruption and tumor cellselective toxicity," European Journal of Medicinal Chemistry, vol. 45, no. 7, pp. 2943-2948, 2010.

[10] T. Kilic, O. Ciftci, A. Cetin, and H. Kahraman, "Preventive effect of chrysin on bleomycin-induced lung fibrosis in rats," Inflammation, vol. 37, no. 6, pp. 2116-2124, 2014.

[11] M. N. Oztanir, O. Ciftci, A. Cetin, M. A. Durak, N. Basak, and Y. Akyuva, "The beneficial effects of $18 \beta$-glycyrrhetinic acid following oxidative and neuronal damage in brain tissue caused by global cerebral ischemia/reperfusion in a C57BL/J6 mouse model," Neurological Sciences, vol. 35, no. 8, pp. 1221-1228, 2014.

[12] K. Yagi, "Simple assay for the level of total lipid peroxides in serum or plasma," Methods in Molecular Biology, vol. 108, pp. 101-106, 1998.

[13] J. Sedlak and R. H. Lindsay, "Estimation of total, proteinbound, and nonprotein sulfhydryl groups in tissue with Ellman's reagent," Analytical Biochemistry, vol. 25, pp. 192-205, 1968.

[14] D. E. Paglia and W. N. Valentine, "Studies on the quantitative and qualitative characterization of erythrocyte glutathione peroxidase," Journal of Laboratory and Clinical Medicine, vol. 70, no. 1, pp. 158-169, 1967.

[15] Y. Sun, L. W. Oberley, and Y. Li, "Simple method for clinical assay of superoxide dismutase. Clin Chem," Clinical Chemistry, vol. 34, pp. 497-500, 1998.

[16] H. Aebi, "Catalase," in Methods of enzymatic analysis, H. U. Bergmeyer, Ed., pp. 673-677, Academic Press, New York, NY, USA, 1974.

[17] O. H. Lowry, N. J. Rosenbrough, A. L. Farr, and R. J. Randall, "Protein measurement with the Folin-phenol reagent," The Journal of Biological Chemistry, vol. 193, pp. 265-275, 1951. 
[18] A. P. Halestrap, S. J. Clarke, and S. A. Javadov, "Mitochondrial permeability transition pore opening during myocardial reperfusion - A target for cardioprotection," Cardiovascular Research, vol. 61, no. 3, pp. 372-385, 2004.

[19] S. Toyokuni, "Reactive oxygen species-induced molecular damage and its application in pathology," Pathology International, vol. 49, no. 2, pp. 91-102, 1999.

[20] R. K. Kurt, A. C. Dogan, M. Dogan et al., "Protective effect of colchicine on ovarian ischemia-reperfusion injury: An experimental study," Reproductive Sciences, vol. 22, no. 5, pp. 545-550, 2015.

[21] V. Bakan, H. Çiralik, F. I. Tolun, Y. Atli, A. Mil, and Ş. Öztürk, "Protective effect of erythropoietin on torsion/detorsion injury in rat model," Journal of Pediatric Surgery, vol. 44, no. 10, pp. 1988-1994, 2009.

[22] S. K. Ha, E. Moon, and S. Y. Kim, "Chrysin suppresses LPSstimulated proinflammatory responses by blocking NF- $\kappa \mathrm{B}$ and JNK activations in microglia cells," Neuroscience Letters, vol. 485, no. 3, pp. 143-147, 2010.

[23] Y. Mizushina, T. Ishida, S. Yagi et al., "Inhibitory effects of glycyrrhetinic acid on DNA polymerase and inflammatory activities," Evidence-Based Complementary and Alternative Medicine, vol. 2012, Article ID 650514, 2012.

[24] D. L. Carden and D. N. Granger, "Pathophysiology of ischaemia-reperfusion injury," The Journal of Pathology, vol. 190, no. 3, pp. 255-266, 2000.

[25] Y. Yao, L. Chen, J. Xiao et al., "Chrysin protects against focal cerebral ischemia/reperfusion injury in mice through attenuation of oxidative stress and inflammation," International Journal of Molecular Sciences, vol. 15, no. 11, pp. 20913-20926, 2014.

[26] N. Yildirim, G. Yigitturk, A. G. Sahingoz Yildirim et al., "Octreotide protects ovary against ischemia-reperfusion injury in rats: Evaluation of histological and biochemical parameters," Journal of Obstetrics and Gynaecology Research, vol. 41, no. 10, pp. 1591-1597, 2015.

[27] P. Özcan, C. Fıçıcıoğlu, Ö. K. Yildirim, F. Özkan, H. Akkaya, and I. Aslan, "Protective effect of resveratrol against oxidative damage to ovarian reserve in female Sprague-Dawley rats," Reproductive BioMedicine Online, vol. 31, no. 3, pp. 404-410, 2015.

[28] G. Sahin Ersoy, M. Eken, R. Tal et al., "N-acetylcysteine leads to greater ovarian protection than enoxaparin sodium in a rat ovarian torsion model," Reproductive BioMedicine Online, vol. 33, no. 1, pp. 93-101, 2016.

[29] B. Tang, H. Qiao, F. Meng, and X. Sun, "Glycyrrhizin attenuates endotoxin-induced acute liver injury after partial hepatectomy in rats," Brazilian Journal of Medical and Biological Research, vol. 40, no. 12, pp. 1637-1646, 2007.

[30] M. Celik, A. N. Aksoy, H. Aksoy, Y. Aksoy, and Z. Halici, "Sildenafil reduces ischemia-reperfusion injury in rat ovary: Biochemical and histopathological evaluation," Gynecologic and Obstetric Investigation, vol. 78, no. 3, pp. 162-167, 2014.

[31] A. Akdemir, O. Erbaş, M. Ergenoğlu et al., "Montelukast prevents ischaemia/reperfusion-induced ovarian damage in rats," European Journal of Obstetrics \& Gynecology and Reproductive Biology, vol. 173, no. 1, pp. 71-76, 2014.

[32] M. A. Osmanağaoğlu, M. Kesim, E. Yuluğ, A. Menteşe, and S. C. Karahan, "Ovarian-protective effects of clotrimazole on ovarian Ischemia/reperfusion injury in a rat ovarian-torsion model," Gynecologic and Obstetric Investigation, vol. 74, no. 2, pp. 125130, 2012.
[33] R. Abali, N. Tasdemir, M. A. Yuksel et al., "Protective effect of infliximab on ischemia/reperfusion injury in a rat ovary model: Biochemical and histopathologic evaluation," European Journal of Obstetrics \& Gynecology and Reproductive Biology, vol. 171, no. 2, pp. 353-357, 2013. 


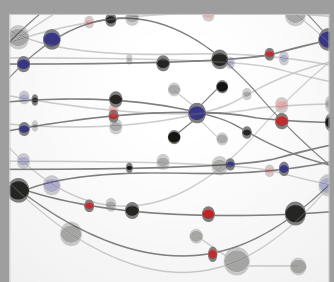

The Scientific World Journal
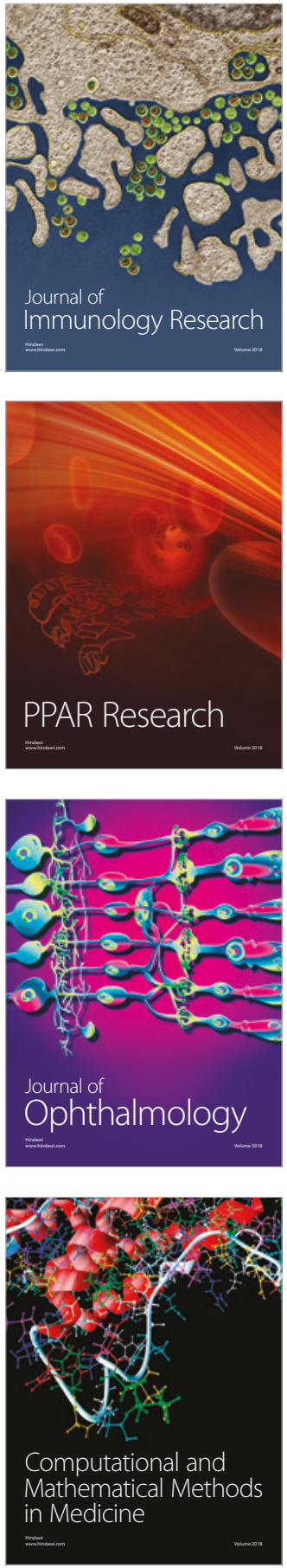

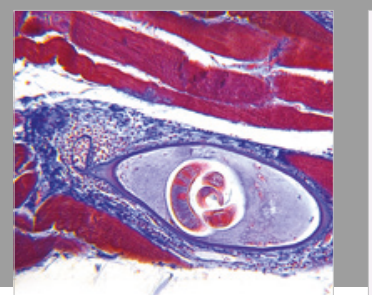

Gastroenterology Research and Practice

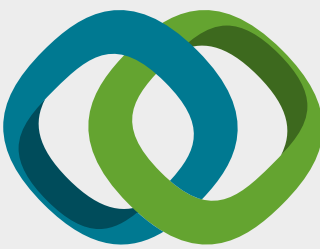

\section{Hindawi}

Submit your manuscripts at

www.hindawi.com
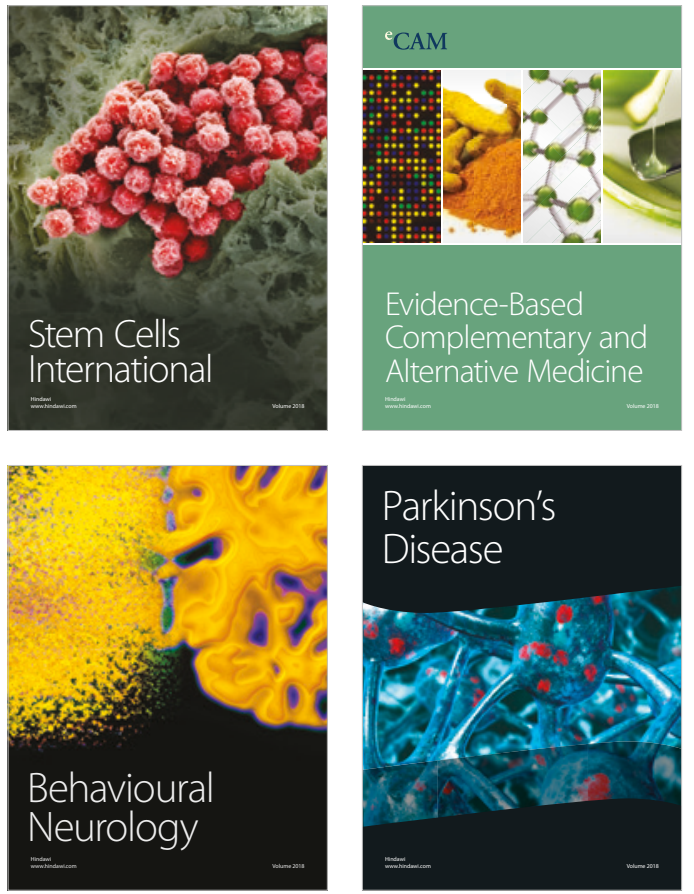

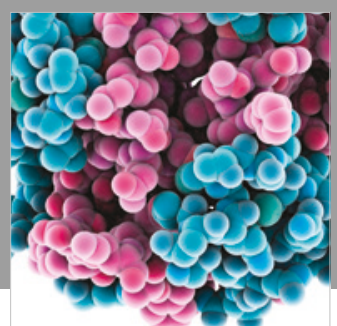

ournal of

Diabetes Research

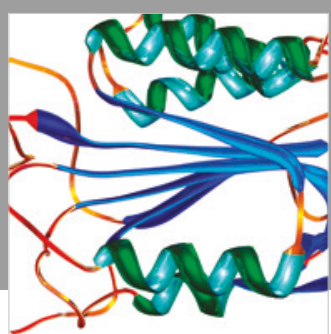

Disease Markers
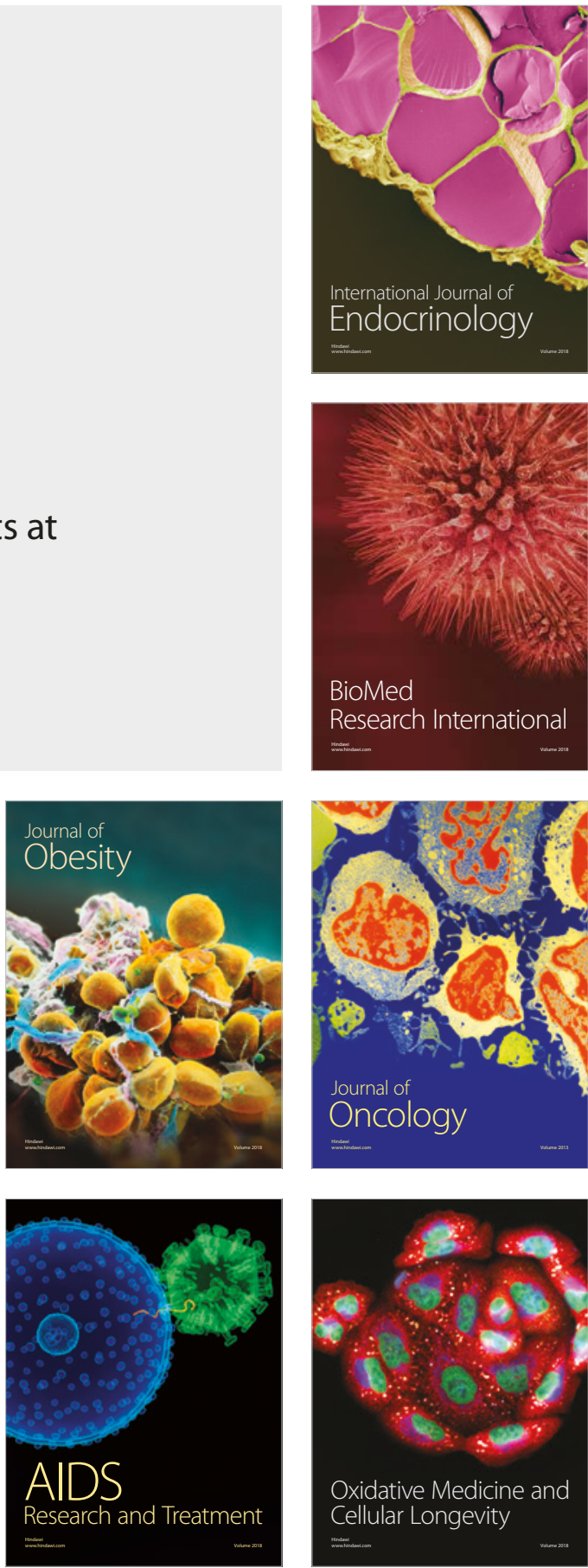